\title{
Insights into transcription termination of Hfq-binding sRNAs of Escherichia coli and characterization of readthrough products
}

\author{
TEPPEI MORITA, MASAKI UEDA, KENTO KUBO, and HIROJI AIBA \\ Faculty of Pharmaceutical Sciences, Suzuka University of Medical Sciences, Suzuka, Mie 513-0816, Japan
}

\begin{abstract}
The genes encoding Hfq-dependent sRNAs possess a typical Rho-independent transcription terminator. Here, we have studied the molecular events occurring at Rho-independent terminators of sRNA genes, focusing on two well-characterized Hfq-binding sRNAs, SgrS and RyhB. We constructed several hybrid genes in which the DNA sequence corresponding to a strong Rhoindependent terminator was placed just downstream from the Rho-independent terminators of sRNA genes. By using this system, we demonstrate that transcripts frequently read through the Rho-independent terminators of $s g r S$ and $r y h B$ in normally growing cells. We show that $\mathrm{Hfq}$ does not affect the transcriptional readthrough event itself. We also find that the readthrough products no longer bind to $\mathrm{Hfq}$ in vivo. We have developed a competition assay based on a biotin-streptavidin system to analyze the interaction of $\mathrm{Hfq}$ and a particular RNA molecule in vitro. By using this method, we verify that the $3^{\prime}$-extended form of SgrS does not bind to $\mathrm{Hfq}$ in vitro. Finally, we demonstrate that transcription termination is significantly enhanced under stress conditions where transcription initiation of sRNA genes on the chromosome is induced. We conclude that the production of sRNAs is regulated not only at the step of transcription initiation but also at the step of transcription termination. The mechanism by which transcription termination is enhanced under stress conditions remains to be understood.
\end{abstract}

Keywords: Hfq; bacterial sRNA; Rho-independent terminator; transcriptional readthrough; termination and stress

\section{INTRODUCTION}

Major regulatory small RNAs (sRNAs) in bacteria bind to the RNA chaperone Hfq and regulate the translation and the stability of target mRNAs through base-pairing by the help of Hfq (Waters and Storz 2009; Gottesman and Storz 2010; Vogel and Luisi 2011). The transcription initiation of sRNA genes is induced under specific physiological and/or stress conditions because the promoter of an individual sRNA gene is under the control of a specific transcription factor that is modulated by respective stress conditions. For example, Escherichia coli SgrS is induced in response to glucose-phosphate stress such as accumulation of glucose-6phosphate (Vanderpool and Gottesman 2004). The induced SgrS sRNA pairs with the target mRNAs to either down- or up-regulate their expression (Vanderpool and Gottesman 2004; Morita et al. 2005; Papenfort et al. 2013). A transcription factor called SgrR is activated, by unknown mechanisms, under the glucose-phosphate stress to stimulate the transcription from the sgrS promoter by RNA polymerase

Corresponding authors: morita-t@suzuka-u.ac.jp, aiba@suzuka-u.ac.jp Article published online ahead of print. Article and publication date are at http://www.rnajournal.org/cgi/doi/10.1261/rna.051870.115. Freely available online through the RNA Open Access option.
(Vanderpool and Gottesman 2007). Another well-characterized Hfq-binding sRNA, RyhB, is induced in response to $\mathrm{Fe}^{2+}$ depletion to regulate the expression of several mRNAs encoding Fe-binding proteins through base-pairing mechanism (Masse and Gottesman 2002; Masse et al. 2003). In this case, Fur, a repressor protein for the $r y h B$ promoter, is inactivated by the $\mathrm{Fe}^{2+}$ depletion, leading to expression of RyhB (Masse and Gottesman 2002).

The expression of sRNA genes might be regulated also at the step of transcription termination. Genes encoding Hfqdependent sRNAs are often located in intergenic regions as a single gene (Waters and Storz 2009) while some sRNA genes form operons along with other genes and/or are embedded in the $3^{\prime}$ region of protein-coding genes (Sun and Vanderpool 2011; Chao et al. 2012; Guo et al. 2014). In either case, the sRNA genes possess a typical Rho-independent transcription terminator that is likely to specify the $3^{\prime}$ ends of most sRNAs. The hallmark features of Rho-independent terminators, also called factor-independent or intrinsic terminators, are a short GC-rich inverted repeat sequence followed by a run of $\mathrm{T}$ residues on the nontemplate strand

(C) 2015 Morita et al. This article, published in $R N A$, is available under a Creative Commons License (Attribution 4.0 International), as described at http://creativecommons.org/licenses/by/4.0/. 
(d'Aubenton Carafa et al. 1990; Reynolds et al. 1992). When RNA polymerase transcribes the inverted repeat sequence of the terminator, the resulting RNA forms a stem-loop (hairpin) structure that is believed to trigger transcription termination within transcribed $U$ stretches by disrupting the elongation complex due to weak A-U base pairs (Rosenberg and Court 1979; Platt 1986; Yager and von Hippel 1991). We noticed previously that the Rho-independent terminators of sRNA genes possess longer $\mathrm{T}$ residue stretches (more than seven) on the nontemplate strand (Otaka et al. 2011) than most other terminators which can vary depending on terminators, but usually less than six (d'Aubenton Carafa et al. 1990). We showed recently that the long polyU tail and hairpin of sRNAs corresponding to their Rho-independent terminator along with a preceding internal U-rich sequence consist of the functional Hfq-binding module of sRNAs (Ishikawa et al. 2012). This implies that the consecutive terminator A residues on the template strand must be efficiently transcribed to generate functional sRNAs. Thus, insights into transcription termination and its regulation will be important to understand how functional sRNAs are generated in cells. To date, however, molecular events at Rho-independent terminators of sRNA genes have been poorly studied. For example, it is largely unknown how frequently transcription termination or readthrough occurs beyond sRNA genes. Because the terminator hairpin and the long polyU tail are essential elements for the Hfq-binding module, another interesting question is whether $\mathrm{Hfq}$ affects the transcription termination/readthrough at Rho-independent terminators of sRNA genes. Furthermore, it is not known whether the $3^{\prime}$-extended forms of sRNAs generated by transcriptional readthrough at sRNA terminators still retain the Hfq-binding ability although an early mutational study suggests that the $3^{\prime}$ extension of DsrA sRNA lead to the loss of its regulatory function (Sledjeski and Gottesman 1995).

The aim of this study is to address these questions, focusing on two well-characterized Hfq-binding sRNAs, SgrS and RyhB. By using a "double terminator system" (Abe et al. 1999), we demonstrated that transcriptional readthrough frequently occurs at Rho-independent terminators of sRNA genes and that the readthrough is not affected by Hfq. In addition, we found that the readthrough products, the $3^{\prime}$-extended forms of sRNAs, no longer bind to $\mathrm{Hfq}$ both in vivo and in vitro. Finally, we found that transcription termination is markedly enhanced under stress conditions in which the transcription of sRNA genes on the chromosome is induced in cells. The biological relevance of this finding will be discussed.

\section{RESULTS}

\section{Double terminator system}

The efficiency of termination at Rho-independent terminators is known to vary widely among individual terminators
(Reynolds et al. 1992). Thus, elongating RNA polymerases pass through different terminator structures with different frequencies, leading to transcription of the downstream sequences. It is generally difficult to evaluate the efficiency of termination by analyzing RNA transcripts directly by Northern blotting because readthrough products are often heterogeneous in size and/or perhaps unstable. We have used a "double terminator system" (Abe et al. 1999) in which a strong Rho-independent terminator derived from $\mathrm{rrnB}$ ( $r n B \mathrm{~T} 1)$ is placed just downstream from a Rho-independent terminator to be tested. The downstream strong terminator efficiently traps the readthrough RNA that is made beyond the test terminator, resulting in stable and distinct longer RNA molecules. To know how frequently transcription termination occurs at Rho-independent terminators of sRNA genes, we constructed hybrid genes on a plasmid in which a strong Rho-independent terminator of rplL (Post et al. 1979) or $r r n B$ (Brosius et al. 1981) was placed just downstream from the Rho-independent terminators of $s g r S$ and $r y h B$ genes encoding SgrS and RyhB sRNAs, respectively. The DNA sequences around the terminators of the genes used along with the predicted RNA secondary structures of transcripts corresponding to the Rho-independent terminators are shown in Figure 1.

\section{Evaluation of transcriptional readthrough at the sgrS terminator}

We first focused on the sgrS terminator. Plasmid pSgrS-S carries the sgrS-S encoding SgrS-S that corresponds to the $3^{\prime}$ portion of SgrS consisting of the minimal base-pairing region and the Hfq-binding module including the Rho-independent terminator sequence (Otaka et al. 2011; Ishikawa et al. 2012). Plasmids pSgrS-S-rrnBT1 and pSgrS-S-rplLT carry the hybrid gene sgrS-S-rrnBT1 and sgrS-S-rplLT, respectively. The sgrS-S gene is under the control of an arabinose-inducible promoter in these plasmids. We first examined transcription termination/readthrough at the sgrS terminator in $h f q^{+}$background by Northern analysis. Plasmids described above were introduced into $h \mathrm{fq}^{+}$cells. As a control, cells were also transformed with the vector plasmid pAraX (Ishikawa et al. 2012). Cells were grown in the presence of arabinose and expression of sRNAs was analyzed by Northern blotting. The sgrS-S gene generates $\sim 60$ nt SgrS-S RNA (Fig. 2A, lane 2). As expected, two hybrid genes, sgrS-S-rrnBT1 and sgrS-SrplLT, also produce the $60 \mathrm{nt}$ SgrS-S (Fig. 2A, lanes 3,4). The expression levels of SgrS-S were essentially identical among these three genes (sgrS-S, sgrS-S-rrnBT1, and sgrS-SrplLT). Thus, transcription termination at the sgrS terminator is not affected by the downstream second terminator rrnBT1 or rplLT. We also confirmed that the target $p t s G$ mRNA was dramatically destabilized when SgrS-S was expressed from any of the three genes (Fig. 2A, lower panel), indicating that SgrS-S generated from the hybrid genes is functional to down-regulate the $p t s G$ mRNA. As expected, 


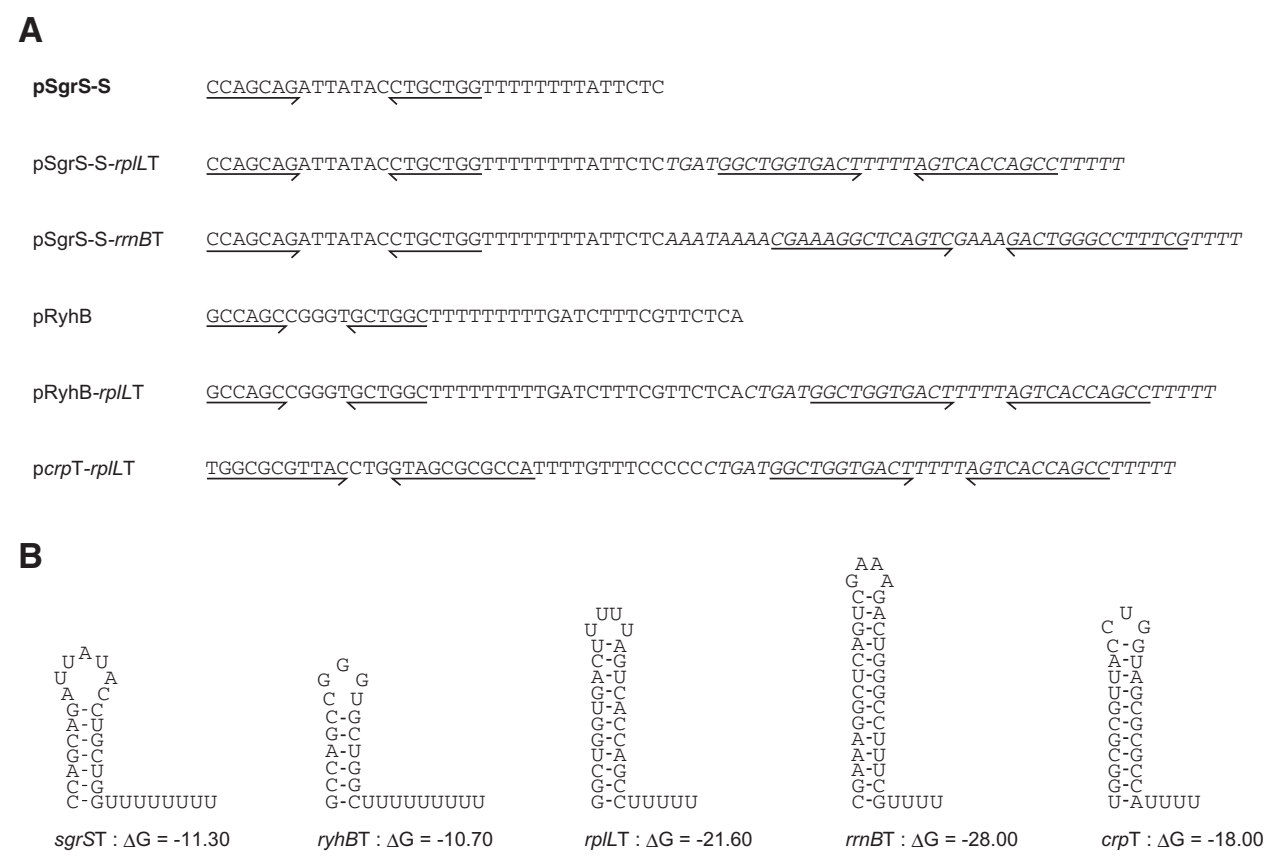

FIGURE 1. (A) DNA sequences around Rho-independent terminators of genes used in this study. The sequences corresponding to Rho-independent terminators of $s g r S$ and $r y h B$ are shown as regular letters, whereas the terminator sequences derived from $r p l L$ and $r r n B$ are shown as italic letters. The inverted repeat sequences of Rho-independent terminators are shown by horizontal arrows. $(B)$ The predicted secondary structures of transcripts corresponding to Rho-independent terminators. The free energies of terminator hairpin structures were determined according to the Mfold program (Zuker 2003).

longer RNA bands corresponding to SgrS-S-rrnBT1 and SgrS-S-rplLT are produced in addition to SgrS-S band in cells harboring pSgrS-S-rrnBT1 or pSgrS-S-rplLT (Fig. 2A, lanes $3,4)$. These bands can be produced mainly because transcripts that passed through the $s g r S$ terminator terminate at the downstream $r r n B T 1$ or rplLT terminator. It is reported that the termination efficiency of $r r n B T 1$ in vivo is $>90 \%$ (Brosius et al. 1981). The rplLT is expected to be also strong because of the high stability of its terminator hairpin structure (Fig. 1B). Indeed, the band corresponding to SgrS-SrplLT is much more distinct than that of SgrS-S-rrnBT1. Hereafter, we have used the rplLT as the downstream terminator to trap the readthrough products.

The presence of Hfq in cells may affect differentially the accumulation of terminated SgrS-S and elongated SgrS-S-rplLT because SgrS-S is stabilized by Hfq binding (Otaka et al. 2011), while it is not sure at this moment whether the stability of SgrS-S- $r p l L T$ is affected by Hfq. We examined the accumulation of terminated and elongated products in both $h f q^{-}$ and $h f q^{+}$backgrounds. As expected, the abundance of SgrS-S generated from either pSgrS-S or pSgrS-S- $r p l L T$ is markedly reduced in the $h f q^{-}$background as compared with the $h f q^{+}$ background (Fig. 2B, lanes 2,4). In contrast, the abundance of SgrS-S-rplLT band generated from pSgrS-S-rplLT is not reduced in the $h f q^{-}$background (Fig. 2B, lane 4), suggesting that SgrS-S-rplLT is not stabilized by Hfq. Thus, it is appropriate to compare the relative abundance of SgrS-S-rplLT and SgrS-S bands in the $h f q^{-}$background rather than in the $h f q^{+}$ background to evaluate the efficiency of termination/readthrough at the $\operatorname{sgr} S$ terminator. Interestingly, the abundance of the SgrS-S-rplLT band is almost identical with that of the SgrS-S band (Fig. 2B, lane 4). This implies that $~ 50 \%$ of elongating RNA polymerase reads through the $s g r S$ terminator if it is assumed that SgrS-S-rplLT and SgrS-S are similar in stability in the $h f q^{-}$background. In fact, we show that this is the case (Fig. 3B).

\section{The readthrough products are not stabilized by $\mathrm{Hfq}$}

The readthrough product (SgrS-S-rplLT) contains the sequence corresponding to the Hfq-binding module (Ishikawa et al. 2012) although the polyU stretch is located internal in the RNA molecule rather than at the $3^{\prime}$ end. An interesting question is if SgrS-S-rplLT still retains the Hfqbinding ability. The observation that the presence of Hfq does not enhance the abundance of SgrS-S-rplLT (Fig. 2B) suggests that SgrS-S-rplLT is not stabilized much by Hfq whereas SgrS-S is. To test this, we evaluated the stability of terminated and elongated forms of SgrS-S in both $h f q^{-}$and $h \mathrm{fq}^{+}$backgrounds. Cells harboring pSgrS-S-rplLT were grown to mid-log phase in the presence of arabinose and rifampicin was added to prevent further initiation of transcription. RNAs were isolated at various times after the addition of rifampicin, and these RNA samples were subjected to Northern blotting. As shown in Figure 3B, the half-lives $\left(t_{(1 / 2)}\right)$ of SgrS-S and SgrS-S-rplLT RNAs are estimated to 

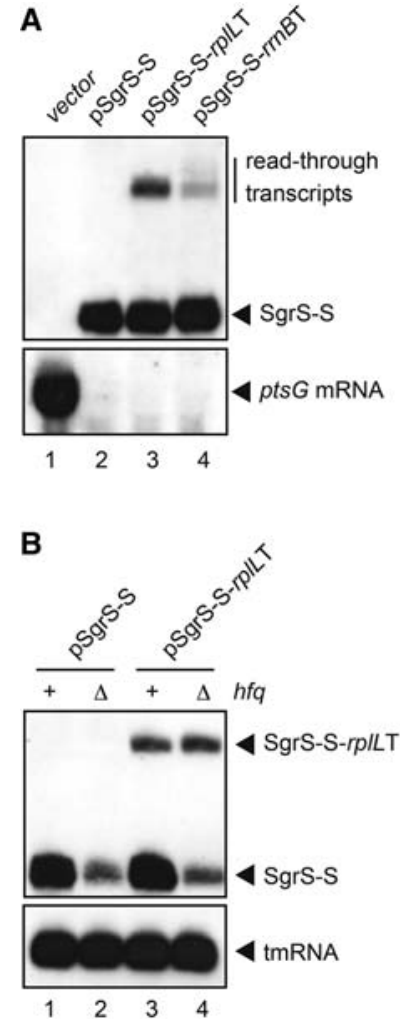

FIGURE 2. (A) Properties of transcripts generated from sgrS-S and hybrid genes. TM542 $\left(\Delta s g r S h f q^{+}\right)$cells harboring indicated plasmids were grown in LB medium in the presence of $0.2 \%$ arabinose. Total RNAs were prepared and $10 \mu \mathrm{g}$ of RNA samples were subjected to Northern blotting using SgrS-S probe and $p t s G$ probe. $(B)$ Effect of Hfq on expression of SgrS-S and SgrS-S-rplLT. TM542 $\left(\Delta s g r S h f q^{+}\right)$and TM772 $(\Delta s g r S$ $\Delta h f q)$ cells harboring indicated plasmids were grown in LB medium in the presence of $0.2 \%$ arabinose. Total RNAs were prepared and 10 and $0.25 \mu \mathrm{g}$ of RNA samples were subjected to Northern blotting using the SgrS-S probe and tmRNA probe, respectively.

be 1.3 and $1.1 \mathrm{~min}$, respectively, in $h f^{-}$cells. Thus, both SgrS-S and SgrS-S-rplLT are highly unstable in the absence of Hfq. On the other hands, SgrS-S is dramatically stabilized in $h f q^{+}$cells $\left(t_{[1 / 2]}>30 \mathrm{~min}\right)$ while SgrS-S-rplLT is still unstable in $h f q^{+}$cells (Fig. 3A).

\section{Analysis of the $r y h B$ terminator}

We also examined transcriptional readthrough at the Rho-independent terminator of the $r y h B$ gene encoding another well-characterized Hfq-binding sRNA, RyhB (Masse and Gottesman 2002) with the double terminator system. Plasmids pRyhB and pRyhB-rplLT carry the $r y h B$ and $r y h B$ rplLT genes, respectively. RNA transcripts from these plasmids in both $h f q^{-}$and $h f q^{+}$cells were analyzed by Northern blotting. The $r y h B$ gene produces 95 nt RyhB while the hybrid $r y h B-r p l L T$ gene produces two RNAs, RyhB plus a longer RNA corresponding to RyhB-rplLT (Fig. 4A). Based on the ratio of the RyhB-rplLT band to the terminated
RyhB band, the efficiency of transcription termination at the $r y h B$ terminator is estimated to be $\sim 80 \%$ in the $h f q^{-}$ background (Fig. 4A, lane 4). The abundance of RyhB generated from both pRyhB and pRyhB-rplLT in $h f q^{-}$cells is significantly reduced compared with the $h f q^{+}$background while the abundance of RyhB-rplLT is moderately affected by the $h f q^{-}$background (20\%-30\% less in $h f q^{-}$cells).

We also evaluated the stability of terminated and elongated forms of RyhB in both $h f q^{-}$and $h f q^{+}$backgrounds. Cells harboring pRyhB-rplLT were grown to mid-log phase in the presence of arabinose and rifampicin was added to prevent further initiation of transcription. RNAs were isolated at various times after the addition of rifampicin, and these RNA samples were subjected to Northern blotting (Fig. 4B,C). The half-lives of RyhB and RyhB-rplLT in the $h f q^{-}$background were estimated to be 4.6 and $2.3 \mathrm{~min}$, respectively (Fig. 4C). It is interesting to note that RyhB is relatively stable compared with SgrS in the $h f q^{-}$background. As expected, RyhB is significantly stabilized $\left(t_{(1 / 2)}=14.6 \mathrm{~min}\right)$ in $h \mathrm{hq}^{+}$ cells (Fig. 4B) although the effect of Hfq on RyhB stabilization is not as great as on SgrS-S. RyhB-rplLT, like SgrS-S$r p l L T$, is only moderately stabilized in $h f q^{+}$cells.

\section{Hfq does not bind to the $3^{\prime}$-extended forms of SgrS and RyhB}

We showed above that the readthrough products, SgrS-SrplLT and RyhB-rplLT, are only moderately stabilized by Hfq. This strongly suggests that the $3^{\prime}$ extension of SgrS and RyhB impairs the Hfq-binding ability of these extended sRNAs. To test this directly, we performed a pull-down assay

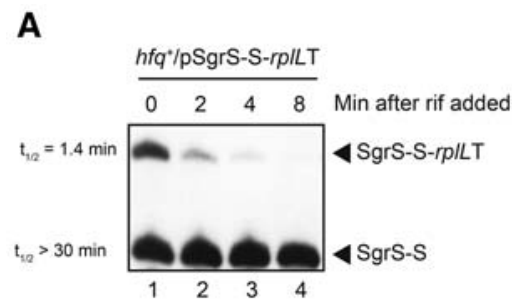

B

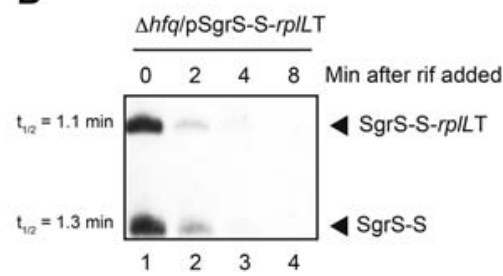

FIGURE 3. Stability of SgrS-S and SgrS-S-rplLT. (A)TM542 ( $\Delta$ sgrS $\left.h f q^{+}\right)$and $(B)$ TM772 ( $\Delta$ sgrS $\left.\Delta h f q\right)$ cells harboring pSgrS-S-rplLT were grown in LB medium in the presence of $0.2 \%$ arabinose to $A_{600}=$ 0.6. Rifampicin $(250 \mu \mathrm{g} / \mathrm{mL})$ was added and the incubation was continued. Total RNAs were prepared at the indicated time after the addition of rifampicin. The RNA samples $(10 \mu \mathrm{g})$ were subjected to Northern blotting using the SgrS-S probe. 


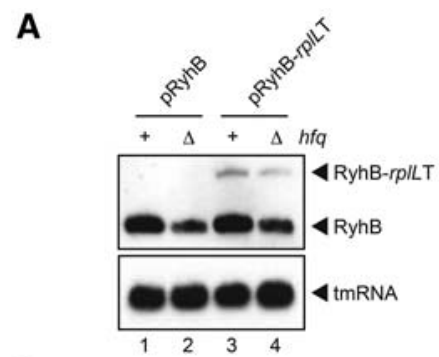

B

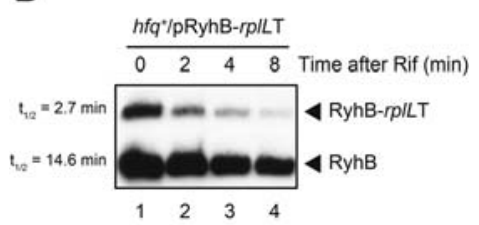

C

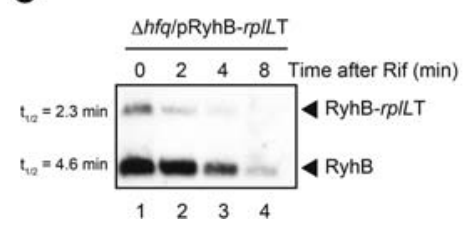

FIGURE 4. (A) Transcripts generated from $r y h B$ and $r y h B$-rplLT genes. TM635 $\left(\Delta r y h B h f q^{+}\right)$and TM820 $(\Delta r y h B \Delta h f q)$ cells harboring indicated plasmids were grown in LB medium in the presence of $1.0 \%$ arabinose. Total RNAs were prepared and 4 and $0.25 \mu \mathrm{g}$ of RNA samples were subjected to Northern blotting using RyhB probe and tmRNA probe, respectively. $(B, C)$ Stability of RyhB and RyhB-rplLT. TM635 $\left(\Delta r y h B h f q^{+}\right)(B)$ and TM820 $(\Delta r y h B \Delta h f q)(C)$ cells harboring pRyhB-rplLT were grown in LB medium in the presence of $1.0 \%$ arabinose to $A_{600}=0.6$. Rifampicin $(250 \mu \mathrm{g} / \mathrm{mL})$ was added and the incubation was continued. Total RNAs were prepared at the indicated time after the addition of rifampicin. The RNA samples $(10 \mu \mathrm{g})$ were subjected to Northern blotting using the RyhB probe.

using cells expressing SgrS-S-rplLT along with SgrS-S, and Hfq-Flag. Cell extracts were incubated with anti-Flag M2-agarose beads. Proteins bound to the agarose beads were analyzed by Western blotting using anti-Flag antibodies. The affinitypurified Hfq-Flag was treated with phenol and subjected to Northern blotting. As shown in Figure 5A, SgrS but not SgrS-S-rplLT co-purified with Hfq-Flag. We also performed a pull-down assay using cells expressing RyhB-rplLT along with RyhB and Hfq-Flag. Again, the terminated RyhB but not the elongated RyhB-rplLT co-purified with Hfq-Flag (Fig. 5B). These results indicate that the $3^{\prime}$ extention surely impairs the Hfq-binding ability of sRNAs in vivo.

We also tested the effect of $3^{\prime}$ extension of SgrS on Hfq binding in vitro by using several synthetic RNAs shown in Figure 6A. SgrS50 contains the entire sequence corresponding to the Hfq-binding module of SgrS including eight consecutive uridine residues at the $3^{\prime}$ end (Otaka et al. 2011; Ishikawa et al. 2012). The predicted secondary structure of SgrS50 is shown on the right of Figure 6A. Biotin-SgrS50 is a derivative of SgrS50 in which the $5^{\prime}$ end of SgrS50 is biotinylated. Both SgrS50 and biotin-SgrS50 are expected to retain the ability to bind Hfq. SgrS46 is a derivative of SgrS50 in which the polyU tail is shortened to $4 \mathrm{U}$ residues and therefore is expected to lose the Hfq-binding ability (Otaka et al. 2011). SgrS60 is a derivative of SgrS50 in which 10 bases are extended after the polyU stretch. First, $\mathrm{Hfq}^{-} \mathrm{His}_{6}$ was incubated with streptavidin-conjugated magnet beads either with or without biotin-SgrS50. Hfq bound and unbound to the magnetic beads was analyzed by SDS-PAGE/silver staining. When Hfq was incubated with the beads in the absence of biotin-SgrS50, Hfq was found only in the unbound fraction (Fig. 6B, lanes 2,8), indicating that $\mathrm{Hfq}^{-} \mathrm{His}_{6}$ itself does not bind to the beads. On the other hand, Hfq in the unbound and bound fractions decreased and increased, respectively, with increasing amounts of biotin-SgrS50 (Fig. 6B, lanes 3-6, and lanes 9-12). These results imply that Hfq binds stably to biotin-SgrS50 that tightly interacts with streptavidin-conjugated magnet beads. Then, we examined the effect of excess amounts of SgrS50, SgrS46, and SgrS60 on the interaction between $\mathrm{Hfq}$ and biotin-SgrS50. When Hfq was incubated with the beads along with biotin-SgrS50 and excess amounts of SgrS50, Hfq was found predominantly in the unbound fraction (Fig. 6C, lanes 3,8). This implies that Hfq binding to biotin-SgrS50 was inhibited because SgrS50 competes well with biotin-SgrS50 regarding Hfq binding. On the other hand, Hfq was found predominantly in the bound fraction when Hfq was incubated with the beads along with biotin-SgrS50 and excess amounts of SgrS46 (Fig. 6C, lanes 4,9). Thus, SgrS46 affects little the interaction between biotinSgrS50 and Hfq, indicating that SgrS46 essentially does not bind to Hfq as expected. Then, we performed the same competition assay by using excess amounts of SgrS60. This $3^{\prime}-$ extended form of SgrS also did not affect the binding of Hfq to biotin-SgrS50 (Fig. 6C, lanes 5,10), indicating that
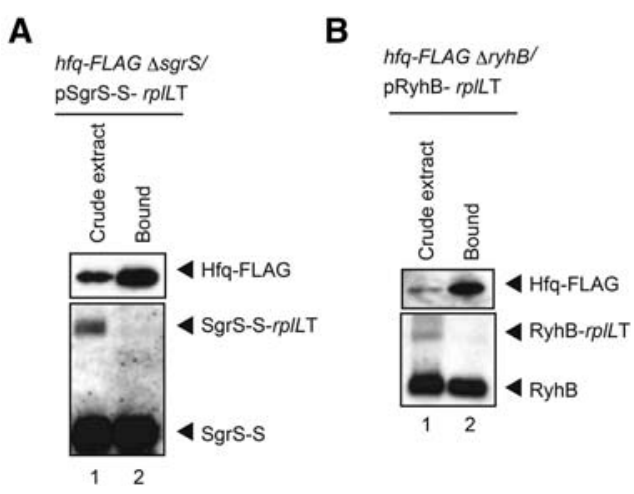

FIGURE 5. In vivo binding of Hfq to terminated sRNAs and readthrough products. Crude extracts were prepared from TM803 $(\Delta s g r S$ $h f q$-Flag) cells harboring pSgrS-S-rplLT $(A)$ and from TM822 ( $\Delta r y h B$ hfq-Flag) cells harboring pRyhB-rplLT $(B)$. Crude extracts were subjected to the pull-down assay using anti-Flag agarose as described in Materials and Methods. Crude extract $(\mathrm{CE} ; 10 \mu \mathrm{L})$ and bound fraction $(\mathrm{B} ; 2 \mu \mathrm{L})$ were analyzed by Western blotting using anti-Flag antibodies. For analysis of RNAs, crude extract $(\mathrm{CE} ; 10 \mu \mathrm{L})$ and bound fraction (B; 2 $\mu \mathrm{L})$ were treated with phenol and subjected to Northern blotting using the SgrS-S $(A)$ or RyhB $(B)$ probe. 


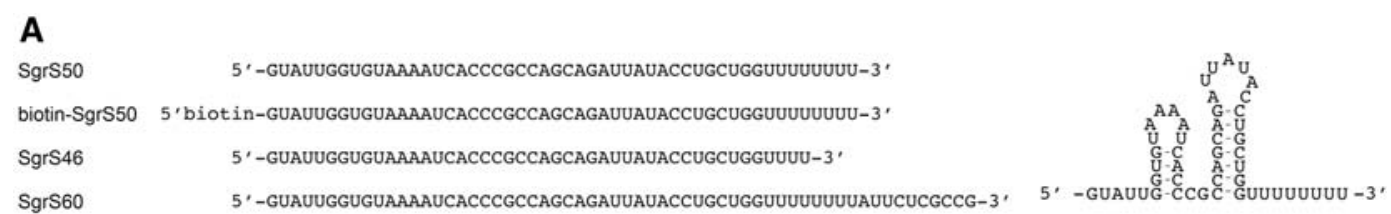

B

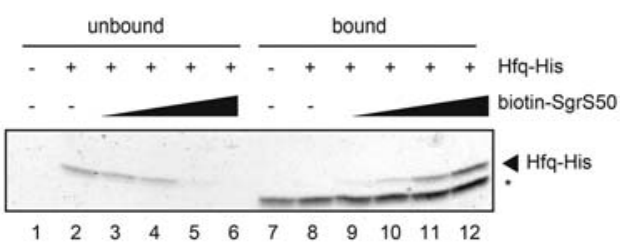

C

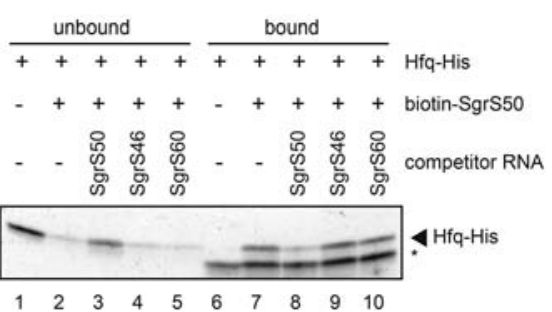

FIGURE 6. Binding of Hfq to synthetic RNAs in vitro. (A) Synthetic RNAs used and their nucleotide sequences. SgrS50 is a $50 \mathrm{nt}$ RNA corresponding to the nucleotides 178-227 of SgrS that is essentially identical with the Hfq-binding module of SgrS (nucleotides 179-227). Biotin-SgrS50 is a derivative of SgrS50 in which the $5^{\prime}$ end was biotinylated. SgrS46 is a derivative of SgrS50 lacking the last 4U of 3' end. SgrS60 is a derivative of SgrS50 in which the $10 \mathrm{nt}$ sequence corresponding to the readthrough transcript is extended. The predicted secondary structure of SgrS50 is shown on the right. (B) Interaction between biotin-SgrS50 and Hfq. Streptavidin magnetic beads and Hfq-His ${ }_{6}(66.7 \mathrm{nM})$ were gently shaken with increasing amounts of biotin-SgrS50 in $15 \mu \mathrm{L}$ of binding buffer for $10 \mathrm{~min}$ at $37^{\circ} \mathrm{C}$. The following amounts of biotin-SgrS50: lanes 3,9, 8.33 nM; lanes 4,10, 16.7 nM; lanes 5,11, $33.3 \mathrm{nM}$; lanes 6,12, $66.7 \mathrm{nM}$. Unbound supernatant and bound precipitate were analyzed by SDS-PAGE and visualized by silver staining. The asterisks $\left({ }^{*}\right)$ indicate the protein (streptavidin) released from the beads during sample heating. $(C)$ Effects of SgrS-S variants on the interaction between biotin-SgrS50 and Hfq. Streptavidin magnetic beads, biotin-SgrS50 $(33.3 \mathrm{nM})$ and Hfq-His ${ }_{6}(66.7 \mathrm{nM})$ were gently shaken with indicated RNAs $(667 \mathrm{nM})$ in $15 \mu \mathrm{L}$ of binding buffer for $10 \mathrm{~min}$ at $37^{\circ} \mathrm{C}$. Unbound supernatant and bound precipitate were analyzed by SDS-PAGE and visualized by silver staining. The asterisks indicate the protein (streptavidin) released from the beads during sample heating.

$3^{\prime}$ extension of SgrS also impairs the Hfa-binding ability of SgrS. These results are consistent with the results of the pull-down assay. Together, we conclude that the Hfq-binding ability of $3^{\prime}$-extended forms of sRNAs is heavily impaired.

\section{Transcription termination is enhanced under stress conditions in which sRNAs are induced}

So far, we have examined transcription termination at Rhoindependent terminators of sRNA genes in normally growing cells. Hfq-binding sRNAs are expressed from their own genes on the chromosome under specific stress and/or physiological conditions. For example, SgrS and RyhB are induced in response to glucose-phosphate stress such as accumulation of glucose-6-phosphate and to depletion of $\mathrm{Fe}^{2+}$, respectively. Because transcription of sRNA genes and their activities are subject to control by Rho-independent termination, we examined the effect of stress on Rho-independent termination of sRNA genes. We first tested the effect of glucose-phosphate stress on transcription termination at the $\mathrm{sgrS}$ terminator. Cells harboring pSgrS-S-rplLT were grown in LB medium containing $0.2 \%$ arabinose to mid-log phase and exposed to $0.1 \%$ nonmetabolizable glucose analog $\alpha$-methylglucoside ( $\mathrm{MMG}$ ) for $10 \mathrm{~min}$. Then, total RNAs were prepared and subjected to Northern blotting using the sgrS probe. Interestingly, the addition of aMG markedly reduced the amount of the readthrough product SgrS-S-rplLT (Fig. 7A, lanes 1,2). In other words, the glucose-phosphate stress enhanced transcription termination at the sgr $S$ terminator.
We also examined the effect of $\mathrm{Fe}^{2+}$ depletion on transcription termination at the $\mathrm{sgrS}$ terminator. Cells harboring pSgrS-S-rplLT were grown in LB medium containing 0.2\% arabinose to mid-log phase and treated with $2,2^{\prime}$-dipyridyl for $10 \mathrm{~min}$ to deplete $\mathrm{Fe}^{2+}$. The addition of 2,2'-dipyridyl clearly enhanced transcription termination at the $\operatorname{sgr} \mathrm{S}$ terminator (Fig. 7A, lane 3). Next, we examined the effects of glucose-phosphate stress and $\mathrm{Fe}^{2+}$ depletion on transcription termination at $r y h B$ terminator by using cells harboring pRyhB-rplLT. As shown in Figure 7B, termination efficiency at $r y h B$ terminator was also enhanced by both glucose-phosphate stress and $\mathrm{Fe}^{2+}$ depletion. Thus, transcription termination at the Rho-independent terminators of sRNA genes is enhanced not only by the cognate stress but also by noncognate stress.

It is interesting to test whether other stress conditions that are associated with the induction of sRNAs affect the transcription termination at the Rho-independent terminators. It is known that several sRNAs including RybB are well expressed during stationary phase compared with log phase (Vogel et al. 2003). Therefore, we have examined the effect of growth phase on transcription termination at Rho-independent terminators. Cells harboring pSgrS-S-rplLT or pRyhB-rplLT were grown in LB medium containing $1.0 \%$ arabinose. Total RNAs were prepared from cells at mid-log and stationary phases, and subjected to Northern blotting using the $s g r S$ or $r y h B$ probe. As shown in Figure 7, C and D, transcription termination at Rho-independent terminators of these sRNA genes is markedly enhanced during stationary 
A

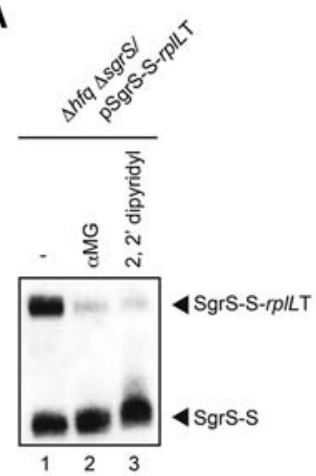

B

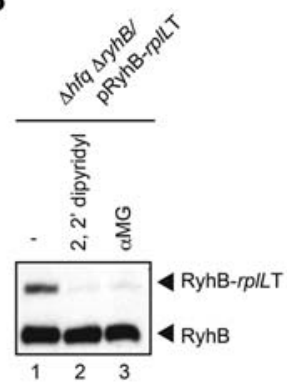

C

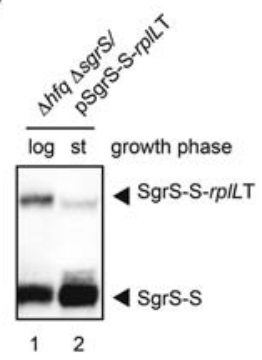

D

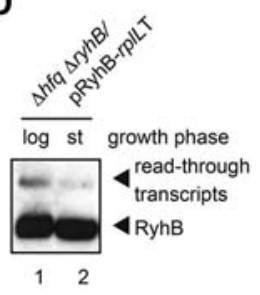

$\mathbf{E}$

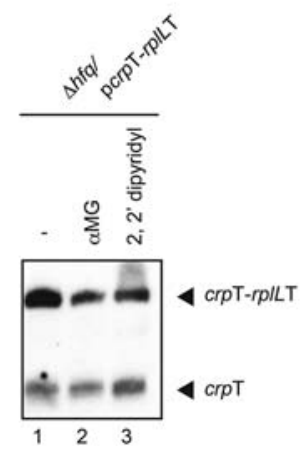

FIGURE 7. Transcriptional readthrough at the Rho-independent terminators of sRNA genes under stress conditions. (A) Effects of glucose-phosphate stress or $\mathrm{Fe}^{2+}$ depletion on readthrough at the sgrS terminator. TM772 $(\Delta s g r S \Delta h f q)$ cells harboring pSgrS-S- $r p l L T$ were grown in LB medium in the presence of $0.2 \%$ arabinose. At $A_{600}=0.6,0.1 \% \alpha$-metylglucoside ( $\alpha \mathrm{MG}$ ) or $250 \mu \mathrm{M}$ $2,2^{\prime}$-dipyridyl (dip) was added to cultures and incubation was continued for $10 \mathrm{~min}$. Total RNAs were prepared and then the RNA samples were subjected to Northern blotting using SgrS-S probe. Ten $\mu \mathrm{g}$ (lanes 1,2) or $25 \mu \mathrm{g}$ (lane 3) of RNAs were loaded. (B) Effects of glucose-phosphate stress or $\mathrm{Fe}^{2+}$ depletion on readthrough at the $r y h B$ terminator. TM820 ( $\left.\Delta r y h B \Delta h f q\right)$ cells harboring pRyhB-rplLT were grown in LB medium in the presence of $1.0 \%$ arabinose. At $A_{600}=0.6$, $250 \mu \mathrm{M}$ dip or $0.1 \%$ aMG was added to cultures and incubation was continued for $10 \mathrm{~min}$. Total RNAs were prepared and then the RNA samples were subjected to Northern blotting using the RyhB probe. Four micrograms (lanes 1,3 ) or $10 \mu \mathrm{g}$ (lane 2) of RNAs were loaded. $(C, D)$ Effect of growth phase on the readthrough at $\operatorname{sgr} S$ and $r y h B$ terminators. TM772 ( $\Delta \operatorname{sgrS} \Delta h f q)$ cells harboring pSgrS-S-rplLT $(C)$ and TM820 $(\Delta r y h B \Delta h f q)$ cells harboring pRyhB-rplLT $(D)$ were grown in LB medium in the presence of $1.0 \%$ arabinose. Total RNAs were prepared from the cultures of $A_{600}=0.6$ (log phase) and $A_{600}=2.5$ (stationary phase). The RNA samples $(10 \mu \mathrm{g})$ were subjected to Northern blotting using the SgrS-S $(C)$ or RyhB $(D)$ probes. $(E)$ Effects of glucose-phosphate stress and Fe depletion on the readthrough at the crp terminator. TM589 $(\Delta h f q)$ cells harboring pcrpT-rplLT were grown in LB medium in the presence of $0.2 \%$ arabinose. At $A_{600}$ $=0.6,0.1 \% \alpha \mathrm{MG}$ or $250 \mu \mathrm{M}$ dip was added to cultures and incubation was continued for 10 min. Total RNAs were prepared and then the RNA samples were subjected to Northern blotting using the $\mathrm{crp}$ probe. Four micrograms (lanes 1,2) or $10 \mu \mathrm{g}$ (lane 3) of RNAs were loaded.

phase. Thus, it is likely that transcription termination at Rhoindependent terminators of sRNAs is generally enhanced under stress conditions. Another interesting question is whether the enhanced termination specific of sRNA genes. To address this question, we have constructed the crpT-rplLT hybrid gene and tested the effect of stress on the Rho-independent terminator of $\mathrm{crp}$. The results show that the termination at the $\mathrm{crp}$ terminator is markedly enhanced by the stress (Fig. $7 \mathrm{E})$. Thus, the enhanced termination under stress conditions may be a general effect at any Rho-independent transcription terminators throughout the genome.

\section{Analysis of readthrough with endogenous transcripts}

We have demonstrated above that transcripts frequently read through the terminators of sRNA genes on the plasmid and transcription termination is enhanced under stress conditions. It is interesting to analyze the transcription termination/ readthrough with the endogenous transcripts generated from chromosomal sRNA genes. For this, we have focused on the sgrS-setA operon. The $h f q^{+}$and $h f q^{-}$cells were grown in LB medium to mid-log phase and exposed to either $0.1 \%$ glucose or $a \mathrm{MG}$ for $10 \mathrm{~min}$. Then, total RNAs were prepared and subjected to Northern blotting. As reported previously (Vanderpool and Gottesman 2004; Kawamoto et al. 2005), SgrS is dramatically induced by aMG (Fig. 8A, lanes $2,4)$. We also confirmed the previous observation (Kawamoto et al. 2005) that the level of SgrS in the $h f q^{+}$cells is much higher than that in the $h f q^{-}$cells because of the stabilization of SgrS by Hfq. In addition, the readthrough transcripts can be clearly observed as heterogeneous smear bands. Thus, the readthrough occurs with the endogenous transcripts as in the case of plasmid-derived transcripts.

It is difficult to examine the effect of stress on the readthrough at the endogenous $\mathrm{sgrS}$ terminator because the endogenous SgrS is not expressed under nonstress conditions. It is known that a mutant G118E SgrR can activate the sgrS transcription even without stress (Sun and Vanderpool 2011). Then, we used cells expressing this mutant SgrR to examine how the stress affects the readthrough at the endogenous $s g r S$ terminator. For this, we constructed $\Delta h f q$ $\Delta \operatorname{sgrR}$ strain (TM816) in which the C-terminal two-thirds of SgrR coding region on the genome was deleted and plasmid pQE-sgrR-G118E carried the mutant $\operatorname{sgrR}$ gene encoding SgrR-G118E. TM816 was transformed with $\mathrm{pQE}-\mathrm{sgrR}-\mathrm{G} 118 \mathrm{E}$. Cells harboring $\mathrm{pQE}-\mathrm{sgrR}$ G118E or pQE80L vector were grown in LB medium containing $0.1 \mathrm{mM}$ Isopropyl $\beta$-D-thiogalactopyranoside (IPTG). Total RNAs were prepared from cells at mid-log phase, and subjected to Northern blotting using the sgrS or setA probe. As expected, SgrS is effectively generated in TM816 cells carrying pQE-sgrR-G118E independently from the stress (Fig. $8 \mathrm{~B})$ while it is not expressed in TM816 cells harboring the 
A

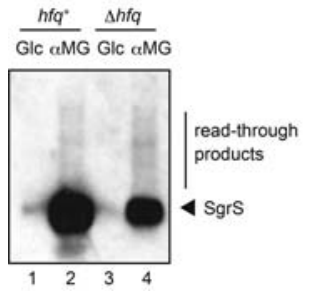

B

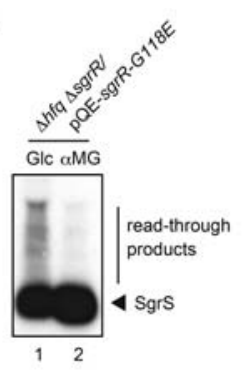

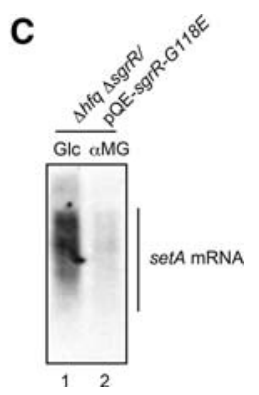

FIGURE 8. Transcriptional readthrough at the endogenous $\operatorname{sgr} S$ terminator and the effect of the stress. (A) IT1568 $\left(h f q^{+}\right)$and TM589 $(\Delta h f q)$ cells were grown in LB medium. At $A_{600}=0.6,0.1 \%$ glucose or $\alpha \mathrm{MG}$ was added to cultures and incubation was continued for $10 \mathrm{~min}$. Total RNAs were prepared and then the RNA samples $(4 \mu \mathrm{g})$ were subjected to Northern blotting using SgrS probe. $(B, C)$ TM816 $(\Delta h f q \Delta s g r R)$ cells harboring pQE-sgrR-G118E were grown in LB medium in the presence of $0.1 \mathrm{mM}$ IPTG. At $A_{600}=0.6,0.1 \%$ glucose or $\alpha \mathrm{MG}$ was added to cultures and incubation was continued for $10 \mathrm{~min}$. Total RNAs were prepared and then the RNA samples $(20 \mu \mathrm{g})$ were subjected to Northern blotting using SgrS probe $(B)$ or $\operatorname{set} A$ probe $(C)$, respectively.

vector plasmid (data not shown). Importantly, the readthrough was markedly reduced under the glucose-phosphate stress (Fig. 8B). The readthrough and its reduction under the stress were also observed in Northern analysis using the set $A$ probe (Fig. 8C). Thus, we conclude that the transcription termination at the endogenous $\mathrm{sgrS}$ terminator transcripts is enhanced under stress conditions.

\section{DISCUSSION}

Genes encoding Hfq-binding sRNAs end with a Rho-independent transcription terminator. A striking feature of Rhoindependent terminators of sRNA genes is the presence of a long consecutive T stretch (more than seven) in the nontemplate strand (Otaka et al. 2011). We showed previously that the RNA sequence corresponding to the Rho-independent transcription terminator makes up a large part of the Hfqbinding module of sRNAs (Ishikawa et al. 2012). Thus, modulation of transcription termination is important for generation of functional Hfq-binding sRNAs in cells. Major questions we have addressed in this study are: (1) how frequently transcriptional readthrough occurs at sRNA genes; (2) whether Hfq affects transcription termination at sRNA genes; (3) whether the readthrough products, the 3 '-extended forms of sRNAs, retain Hfq-binding ability; and (4) how stress conditions associated with the induction of sRNAs affect transcription termination. We used a "double terminator system" in which a strong Rho-independent terminator was placed just downstream from the Rho-independent terminators of the plasmid-borne sRNA genes $s g r S$ and $r y h B$.

We found first that $\sim 50 \%$ and $20 \%$ of elongating RNA polymerases read through the Rho-independent terminators of $s g r S$ and $r y h B$ during normal growth (Figs. 2B,4A). Although the stability of the terminator hairpin and the length of polyU

tail are important factors that dictate the termination efficiency, there seems to be a little difference between $\operatorname{sgrS}$ and $r y h B$ terminators regarding the stability and the length of polyU tail. In fact, the free energy of the terminator hairpin $(\Delta \mathrm{G})$ of SgrS and RyhB are calculated to be -11.3 and -10.7 , respectively, while the length of the polyU tail of SgrS and RyhB are 8 and 9, respectively (Fig. 1B). It is known that several factors including flanking sequences of a terminator hairpin affect termination efficiency at Rho-independent terminators (Reynolds et al. 1992). The presence of a short hairpin before the terminator hairpin of SgrS (Ishikawa et al. 2012) may limit the formation of terminator hairpin leading to the reduced transcription termination (increased readthrough) at the sgrS terminator.

It is an intriguing question if Hfq plays any roles in transcription termination at the Rho-independent terminators in particular of sRNA genes because Hfq interacts with nascent transcripts of the sRNA genes. However, it has not been tested experimentally whether Hfq affects transcription termination at Rho-independent terminators until the present work. It is reported that Hfq reduces transcription termination by directly inhibiting the activity of termination factor Rho at Rho-dependent terminators (Rabhi et al. 2011). Yet, here we see that the levels of readthrough product are little or only slightly affected by the presence of $\mathrm{Hfq}$ at the $\mathrm{sgrS}$ and $r y h B$ terminators while the abundance of terminated transcripts is elevated because these RNAs are stabilized against degradation by Hfq binding. The observation that Hfq does not affect readthrough simply implies that Hfq is not involved in modulation of transcription termination at Rho-independent terminators.

The finding that the transcriptional readthrough occurs frequently at the $\operatorname{sgrS}$ and $r y h B$ terminators implies that significant amounts of readthrough products are continuously generated in cells. The products generated by readthrough are variants of sRNAs in which their $3^{\prime}$ ends are extended. The $3^{\prime}$-extended forms of SgrS and RyhB retain the entire sequence corresponding to the Hfq-binding module (Ishikawa et al. 2012) though the polyU stretch is no longer located at the $3^{\prime}$ end in these RNA molecules. This raised the question of whether the $3^{\prime}$-extended forms of SgrS and RyhB still retained their regulatory function as Hfq-binding sRNAs. Hfq is known to stabilize sRNAs upon binding in cells (Storz and Gottesman 2006). We demonstrated that the $3^{\prime}$ extended forms of SgrS and RyhB are poorly stabilized by Hfq (Figs. 3, 4), and by pull-down assays that the Hfq-binding ability of the 3'-extended forms of SgrS and RyhB is dramatically decreased (Fig. 5). We also showed by a competition assay using a biotin-streptavidin system that a synthetic RNA corresponding to the $3^{\prime}$-extended form of SgrS does not bind to Hfq in vitro (Fig. 6). We conclude that the $3^{\prime}$-extended forms of SgrS and RyhB produced by transcriptional readthrough no longer retain the Hfq-binding ability and thereby may not function to regulate the target mRNAs. This conclusion is consistent with the early mutational study on DsrA 
sRNA that showed that mutations in the terminator stemloop of DsrA led to a significant readthrough resulting in the loss of the regulatory function of DsrA (Sledjeski and Gottesman 1995). In addition, it is reported that the affinity and/or the mode of Hfq binding to a hexauridine (U6) was significantly altered by a single nucleotide substitutions (U5A, U5C, and U5G) at the 3 '-terminal position (Sauer and Weichenrieder 2011). This is also consistent with the present finding that the readthrough products of Hfq-binding sRNAs no longer bind to Hfq. Thus, we conclude that the polyU stretch must be located at the $3^{\prime}$ end to act as an element to bind Hfq.

Studies to understand how Hfq-binding sRNAs interact with the target mRNAs and Hfq are crucial in understanding how sRNAs act. Various biochemical and biophysical methods have been used to analyze sRNA-mRNA and/or sRNAHfq interactions. For example, we previously used an electrophoretic mobility shift assay to analyze the sRNA-mRNA and sRNA-Hfq interactions using RNAs prepared by either in vitro transcription or chemical synthesis (Maki et al. 2010). Another approach for studying RNA-RNA and RNA-protein interactions is the use of biotin-labeled RNAs along with streptavidin beads. Indeed, this approach has proved to be useful to study the sRNA-mRNA interaction (Vincent et al. 2013). In this study, as we have outlined in results, we used the biotin-streptavidin system to study the interaction between sRNAs and Hfq. Our system consists of a 5'-biotinylated synthetic RNA containing a minimal Hfq-binding module, a test RNA, purified Hfq and streptavidin-conjugated magnet beads. The biotinylated RNA binds tightly to the streptavidin beads without losing the Hfq-binding activity. Thus, Hfq can be immobilized on the beads through biotinylated RNA. When excess amounts of test RNAs retaining but not losing Hfq-binding activity can compete with the biotinylated RNA resulting in the inhibition of the $\mathrm{Hfq}$ binding to the beads. We showed that this method is quite simple, rapid, and useful to examine the Hfq-binding ability of individual RNA molecules. To our knowledge, this is the first case in which a biotinylated RNA has been successfully used to study the sRNA-Hfq interaction although sRNAs tagged by aptamers such as MS2 and boxB were shown to be useful for the in vivo study on Hfq-sRNA interaction (Said et al. 2009).

The sgrS gene is known to be co-transcribed with the downstream gene setA encoding a putative sugar transporter (Sun and Vanderpool 2011). SetA was shown to contribute to the cellular response to the glucose-phosphate stress although how it acts remains to be determined (Sun and Vanderpool 2011). Similarly, the $r y h B$ seems to be co-transcribed with the downstream gene $y h h X$ (Vassinova and Kozyrev 2000) though this has not been shown experimentally so far. We demonstrated in the present study that transcription termination at the Rho-independent terminators of $\operatorname{sgrS}$ and $r y h B$ is markedly enhanced under the stress conditions. The enhanced termination under the stress conditions was also observed in the genomic sgrS-setA transcript (Fig. 8).
Thus, the sRNA production is regulated not only at the step of transcription initiation but also at the step of transcription termination. This is biologically significant since increased transcription termination at sRNA genes under stress conditions generate more stable functional sRNAs to deal with the stresses. The enhanced transcription termination at sRNA genes implies that the expression of downstream genes is quite low. In fact, the analysis of the sgrS-set $A$ bi-cistronic transcript showed high SgrS levels relative to setA mRNA levels under glucose-phosphate stress (Sun and Vanderpool 2011). According to our data, the abundance of SgrS-S-rplLT in $h \mathrm{hq}^{+}$cells is a few \% of that of SgrS-S under the stress conditions, indicating most transcripts terminate at the sgrS terminator. It remains to be determined whether this differential expression of the sRNA gene and the downstream gene has biological significance under these stress conditions. We also do not know at this stage the mechanism by which transcription termination is enhanced under stress conditions. Interestingly, the transcription termination at $\operatorname{sgr} S$ and $r y h B$ terminators is enhanced not only by a particular cognate stress but also other stress conditions. This suggests that the physiology of cells undergoing stress conditions affects transcription termination at the Rho-independent terminators. One plausible effect of stress might be to reduce nucleoside triphosphates (NTPs) levels in cells, since low NTP concentrations are reported to enhance transcription termination at Rho-independent terminators in vitro (Reynolds et al. 1992). It is interesting to examine if stress conditions such as accumulation of glucose-6-phosphate and depletion of $\mathrm{Fe}^{2+}$ ion lead to the reduction of NTP concentration in cells, and if this is a general effect at Rho-independent transcription terminators throughout the genome.

\section{MATERIALS AND METHODS}

\section{Bacterial strains and plasmids}

The E. coli K12 strains and plasmids used in this study are listed in Table 1. IT1568 (W3110 $\mathrm{mlc}^{-}$) was used as a parent wild-type strain. To construct TM772 and TM820, the $\Delta h f q:: c a t$ allele of TM587 (Morita et al. 2005) was moved to TM542 (Kawamoto et al. 2005) and TM635 (Morita et al. 2006), respectively, by P1 transduction. To construct TM821, the hfq-Flag-cat allele of TM615 (Morita et al. 2005) was moved to TM635 (Morita et al. 2006) by P1 transduction. TM803 and TM822 were constructed by removing the cat gene flanked by two FRT sequences from TM771 (Otaka et al. 2011) and TM821, respectively. The $\Delta s g r R:: k a n$ allele was constructed from BW25113/pKD46 according to Datsenko-Wanner protocol using pKD4 harboring kan gene (Datsenko and Wanner 2000). To construct TM814, the $\Delta s g r R:: k a n$ allele was moved to IT 1568 by P1 transduction. To construct TM816, the $\Delta h f q::$ cat allele of TM587 (Morita et al. 2005) was moved to TM814 by P1 transduction.

The DNA primers used are listed in Table 2. Plasmids pSgrS-SrplLT and pSgrS-S-rrnBT1 were constructed as follows: pSgrS-S was used to amplify the DNA fragments containing the sgrS-S sequence and the rplLT or rrnBT1 sequence with primers 1127 and 
TABLE 1. Bacterial strains and plasmids used in this study

\begin{tabular}{|c|c|c|}
\hline Strain/plasmid & Relevant genotype and property & Source/reference \\
\hline \multicolumn{3}{|l|}{ Strain } \\
\hline IT1568 & W3110m/c & Laboratory stock \\
\hline TM542 & W3110m/c $\Delta(\operatorname{sgr} R-s g r S)$ & Kawamoto et al. (2005) \\
\hline TM587 & W3110m/c $\Delta h f q:: c a t$ & Morita et al. (2005) \\
\hline TM772 & W3110m/c $\Delta(\operatorname{sgr} R-\operatorname{sgr} S) \Delta h f q::$ cat & This study \\
\hline TM635 & W3110m/c $\Delta r y h B$ & Morita et al. (2006) \\
\hline TM820 & W3110m/c $\Delta r y h B \Delta h f q::$ cat & This study \\
\hline TM771 & W3110m/c $\Delta$ (sgrR-sgrS) hfq-Flag-cat & Otaka et al. (2011) \\
\hline TM803 & W3110m/c $\Delta$ (sgrR-sgrS) hfq-Flag & This study \\
\hline TM615 & W3110m/c hfq-Flag-cat & Morita et al. (2005) \\
\hline TM821 & W3110m/c $\Delta r y h B ~ h f q-F l a g-c a t$ & This study \\
\hline TM822 & W3110m/c $\Delta r y h B$ hfq-Flag & This study \\
\hline TM589 & W3110m/c $\Delta h f q$ & Morita et al. (2005) \\
\hline TM814 & W3110m/c $\Delta s g r R:: k a n$ & This study \\
\hline TM816 & W3110m/c $\Delta$ sgrR::kan $\Delta h f q::$ cat & This study \\
\hline \multicolumn{3}{|l|}{ Plasmid } \\
\hline pAraX & Derivative of pMW218 carrying araC- $P_{B A D}$ & Otaka et al. (2011) \\
\hline pSgrS-S & Derivative of pAraX carrying sgrS-S & Otaka et al. (2011) \\
\hline pSgrS-S-rp/LT & Derivative of pAraX carrying sgrS-S-rp/LT & This study \\
\hline pSgrS-S-rrnBT1 & Derivative of pAraX carrying sgrS-S-rrnBT1 & This study \\
\hline pRyhB & Derivative of pAraX carrying ryhB & Otaka et al. (2011) \\
\hline pRyhB-rp/LT & Derivative of pAraX carrying ryhB-rp/LT & This study \\
\hline pcrpT-rp/LT & Derivative of pAraX carrying crpT-rp/LT & This study \\
\hline pQE80L & High-copy-number plasmid vector & QIAGEN \\
\hline pQE-SgrR-G118E & Derivative of pQE80L carrying sgrR-G118E & This study \\
\hline
\end{tabular}

1415 or 1707 , respectively. The amplified DNA fragments were digested with $\mathrm{XbaI}$ and HindIII and cloned into pAraX. Plasmid pRyhB- $r p l L T$ was constructed as follows: $p$ RyhB was used to amplify the DNA fragment containing the $r y h B$ sequence and the $r p l L$ terminator sequences with primers 1144 and 1527 . The amplified DNA fragment was digested with XbaI and HindIII and cloned into pAraX. Plasmid pcrpT-rplLT was constructed as follows: pHA7 (Aiba et al. 1982) was used to amplify the DNA fragment containing the crp terminator region and the $r p l L$ terminator sequence with primers 1717 and 1718. The amplified DNA fragment was digested with $\mathrm{XbaI}$ and HindIII and cloned into pAraX. Plasmid pQE-sgrRG118E was constructed as follows: chromosomal DNA of W3110 mlc was used to amplify the DNA fragment 1 containing the mutated sgrR region (from -19 to +366 relative to ATG start codon) with primers 1596 and 1597. Similarly, DNA fragment 2 containing the mutated $\operatorname{sgr} R$ region $(+341$ to +1656 relative to ATG start codon)

TABLE 2. DNA primers used for construction of plasmids

\begin{tabular}{|c|c|c|}
\hline Primer & Sequence & Plasmid \\
\hline 1127 & GCGCTCTAGATAGTGTGACTGAGTATTGGT & $\begin{array}{l}\text { pSgrS-S-rp/LT(F) } \\
\text { pSgrS-S-rrnBT(F) }\end{array}$ \\
\hline 1415 & $\begin{array}{l}\text { CCСAAGCTTAGCGCAAAAAGGCTGGTGACTAAAAAGTCACCAGCCATCAGAG } \\
\text { AATAAAAAAAACCAGCAGGTATAATCTG }\end{array}$ & pSgrS-S-rp/LT(R) \\
\hline 1707 & $\begin{array}{l}\text { CCССAAGCTTAAAACGAAAGGCCCAGTCTTTCGACTGAGCCTTTCGTTTTATTT } \\
\text { GAGAATAAAAAAAACCAGCAGGTATAATCTGCT }\end{array}$ & pSgrS-S-rrnBT(R) \\
\hline 1144 & GCGCTCTAGATAGCGATCAGGAAGACСCTC & pRyhB-rp/LT(F) \\
\hline 1527 & $\begin{array}{l}\text { CCCAAGCTTAGCGCAAAAAGGCTGGTGACTAAAAAGTCACCAGCCATCAGTGA } \\
\text { GAACGAAAGATCAAAAAAAAAGCCAGCACCCGGCTGG }\end{array}$ & pRyhB-rp/LT(R) \\
\hline 1717 & GCGCTCTAGATACCGCACACGGTAAAACCATC & pcrpT-rp/LT(F) \\
\hline 1718 & $\begin{array}{l}\text { CCСAAGCTTAGCGCAAAAAGGCTGGTGACTAAAAAGTCACCAGCCATCAGGGGG } \\
\text { GAAACAAAATGGCGCGCTACCAGGTAAC }\end{array}$ & pcrpT-rp/LT(R) \\
\hline 1595 & GCTTCCGCCAGGAGCGGCACATCCTG & $\mathrm{pQE}-\mathrm{sgr} R-\mathrm{G} 118 \mathrm{E}$ \\
\hline 1596 & CAGGATGTGCCGCTCCTGGCGGAAGC & pQE-sgrR-G118E \\
\hline 1597 & GCGCGAATTCGCACAGGAGTTCCССTT & pQE-sgrR-G118E \\
\hline 1598 & CCСAAGCTTTTATCATGGATCCGGTGGCGCAAA & pQE-sgrR-G118E \\
\hline 1604 & TGGCGTTTCTTTTTTGCGTCCAGGAGTCCATTTTCACCGTGTAGGCTGGAGCTGCTTC & $\Delta$ sgrR::kan P1 \\
\hline 1605 & AGAACGGCGTTAGTGTAGTGATTTTGTTATCAACCACATATGAATATCCTCCTTA & $\Delta$ sgrR::kan P2 \\
\hline
\end{tabular}


was amplified with primers 1595 and 1598. Then, the DNA fragments land 2 were used to amplify the mutated $\operatorname{sgr}$, in which G at +353 is changed to A with 1597 and 1598. The amplified DNA fragment containing sgrS G118E was digested with EcoRI and HindIII and cloned into pQE80L.

\section{Northern blotting}

Cells carrying the indicated plasmids were grown at $37^{\circ} \mathrm{C}$ to mid-log phase unless specified in LB medium supplemented with kanamycin $(15 \mu \mathrm{g} / \mathrm{mL})$ and indicated amounts of arabinose. In Figure 8B,C, cells carrying the indicated plasmids were grown at $37^{\circ} \mathrm{C}$ to mid-log phase with ampicillin $(50 \mu \mathrm{g} / \mathrm{mL})$ and indicated amounts of IPTG. Total RNAs were isolated as described (Aiba et al. 1981). To detect SgrS-S, RyhB, and crp RNAs, RNA samples were resolved by $12 \%$, $6 \%$, and $8 \%$ polyacrylamide gel electrophoresis in the presence of 8 $\mathrm{M}$ urea and blotted onto Hybond- $\mathrm{N}^{+}$membrane (GE Healthcare). To detect $p t s G$ mRNA and set $A$ mRNA, RNA samples were resolved by $1.2 \%$ agrarose gel electrophoresis in the presence of formaldehyde and blotted onto Hybond- $\mathrm{N}^{+}$membrane (GE Healthcare). To detect SgrS and tmRNA, RNA samples were resolved by $1.5 \%$ agrarose gel electrophoresis in the presence of formaldehyde and blotted onto Hybond- $\mathrm{N}^{+}$membrane (GE Healthcare). The RNAs were visualized using digoxigenin (DIG) reagents and kits for nonradioactive nucleic acid labeling and a detection system (Roche Applied Science) according to the procedure specified by the manufacturer. The SgrS-S RNA probe corresponding to antisense of $3^{\prime}$ portion $(+168$ to +227$)$ of sgrS was prepared by DIG RNA labeling kit (Roche Applied Science). The following DIG-labeled DNA probes were prepared by PCR using DIG-dUTP: a 305-bp fragment corresponding to the $5^{\prime}$ region of $p t s G$ (ptsG probe); 95-bp fragment corresponding to the ryhB (RyhB probe); 227-bp fragment corresponding to the $\operatorname{sgrS}$ (SgrS probe); 363-bp fragment corresponding to the tmRNA (tmRNA probe); 90-bp fragment corresponding to the $3^{\prime}$ region of $\mathrm{crp}$ (crp probe); 220 -bp fragment corresponding to +11 to +230 region relative to ATG start codon of $\operatorname{set} A$ (setA probe). Multi Gauge ver. 3.1 software (Fujifilm) was used to quantify RNA bands on the films.

\section{Pull-down assay}

Cells were grown in $400 \mathrm{~mL}$ of LB medium in the presence of $1.0 \%$ arabinose, harvested, and washed with $10 \mathrm{~mL}$ STE buffer $(100 \mathrm{mM}$ $\mathrm{NaCl}, 10 \mathrm{mM}$ Tris- $\mathrm{HCl}$ at $\mathrm{pH}$ 8.0, and $1 \mathrm{mM}$ EDTA). The cell pellets were suspended in ice cold $10 \mathrm{~mL}$ of IP buffer $(20 \mathrm{mM}$ Tris- $\mathrm{HCl}$ at $\mathrm{pH}$ 8.0, $0.1 \mathrm{M} \mathrm{KCl}, 5 \mathrm{mM} \mathrm{MgCl}_{2}, 10 \%$ glycerol, and $0.1 \%$ Tween 20 ). The cell suspension was sonicated and centrifuged at $10,000 \mathrm{~g}$ for $10 \mathrm{~min}$ at $4^{\circ} \mathrm{C}$. The supernatant (crude extract: $\mathrm{CE}$ ) was incubated with $50 \mu \mathrm{L}$ of anti-Flag M2-agarose suspension (Sigma-Aldrich) for $30 \mathrm{~min}$ at $4^{\circ} \mathrm{C}$. The mixture was filtered by using a mini chromatography column (Bio-Rad). The agarose beads were washed twice by $10 \mathrm{~mL}$ of IP buffer. The proteins bound to the beads were eluted with $50 \mu \mathrm{L}$ of IP buffer containing $0.4 \mathrm{mg} / \mathrm{mL}$ Flag peptide (SigmaAldrich) and used as bound fraction (B). To analyze proteins, the crude extract $(10 \mu \mathrm{L})$ and the bound fraction $(2 \mu \mathrm{L})$ were mixed with SDS-PAGE loading buffer $(6.25 \mathrm{mM}$ Tris- $\mathrm{HCl}$ at $\mathrm{pH} 6.8,2 \%$ SDS, $10 \%$ glycerol, 5\% $b$-mercaptoethanol, $0.1 \%$ Bromophenol blue). The samples were heated for $5 \mathrm{~min}$ at $100^{\circ} \mathrm{C}$ and subjected to a $15 \%$ SDS gel electrophoresis, and then transferred to an Immobilon membrane (Milipore). The membrane was treated with an anti-Flag monoclonal antibody (Sigma-Aldrich). Signals were visualized by the Lumi-light Western Blotting Substrate (Roche). To analyze RNAs, the crude extract $(10 \mu \mathrm{L})$ and the bound fraction $(2 \mu \mathrm{L})$ were treated with phenol, precipitated, and washed with ethanol. Each precipitate was dissolved in $6 \mu \mathrm{L}$ of RNA buffer ( $0.02 \mathrm{M}$ sodium acetate at $\mathrm{pH} 5.5,0.5 \% \mathrm{SDS}$, and $1 \mathrm{mM}$ EDTA). The RNA samples were subjected to Northern blotting.

\section{Purification of His-tagged Hfq}

TM589 harboring pQE80L-Hfq-His (Kawamoto et al. 2006) was cultured in $200 \mathrm{~mL}$ of $\mathrm{LB}$ medium at $37^{\circ} \mathrm{C}$ in the presence of $25 \mu \mathrm{M}$ IPTG and $50 \mu \mathrm{g} / \mathrm{mL}$ ampicillin. At $A_{600}=0.2,2 \mathrm{mM}$ of IPTG was added to the culture and incubation was continued for $70 \mathrm{~min}$. Cells were harvested and washed with $20 \mathrm{~mL} \mathrm{STE}$, and suspended in Lysis Buffer Native ( $\mathrm{pH}$ 8.0) (Qiagen). The cell suspension was treated with lysozyme $(1 \mathrm{mg} / \mathrm{mL})$ for $10 \mathrm{~min}$ at $0^{\circ} \mathrm{C}$, sonicated, and centrifuged at $10,000 \mathrm{~g}$ for $10 \mathrm{~min}$ at $4^{\circ} \mathrm{C}$. The supernatant was treated with RNase $\mathrm{A}(1 \mu \mathrm{g} / \mathrm{mL})$ for $10 \mathrm{~min}$ at $0^{\circ} \mathrm{C}$ and then heated for $10 \mathrm{~min}$ at $80^{\circ} \mathrm{C}$. The sample was centrifuged at $10,000 \mathrm{~g}$ for $10 \mathrm{~min}$ at $4^{\circ} \mathrm{C}$. The supernatant was incubated with $500 \mu \mathrm{L}$ of $\mathrm{Ni}^{2+}$-NTA agarose resin (Qiagen) for $20 \mathrm{~min}$ at $4^{\circ} \mathrm{C}$ and $\mathrm{Hfq}^{-} \mathrm{His}_{6}$ protein was purified according to the manufacturer's instruction. Purified Hfq-His ${ }_{6}$ was concentrated by Amicon Ultra (0.5 mL 3K) Centrifugal Filters (Milipore). The Hfq-His ${ }_{6}$ concentration was estimated by $15 \%$ SDS-PAGE and SimplyBlue SageStain (Invitrogen). Purified $\mathrm{Hfq}_{-}-\mathrm{His}_{6}$ was stored with storage buffer $\left(20 \mathrm{mM}\right.$ Tris- $\mathrm{HCl}$ at $\mathrm{pH} 8.0,0.1 \mathrm{M} \mathrm{KCl}, 5 \mathrm{mM} \mathrm{MgCl}_{2}$, $50 \%$ glycerol, and $0.1 \%$ Tween $20,1 \mathrm{mM} \mathrm{DTT}$ ) at $-30^{\circ} \mathrm{C}$.

\section{In vitro competition assay}

Synthetic RNAs including 5' - biotinylated RNA were obtained from GeneDesign Inc. Two microliters of Dynabeads MyOne Streptavidin $\mathrm{C} 1$ magnetic beads (Lifetechnologies), purified Hfq-His ${ }_{6}(66.7 \mathrm{nM})$, indicated amounts of biotinylated RNA, and an excess amount (667 $\mathrm{nM}$ ) of different competitor RNAs were mixed together in $15 \mu \mathrm{L}$ of binding buffer (20 mM Tris- $\mathrm{HCl}$ at $\mathrm{pH} 8.0,1 \mathrm{mM}$ DTT, $1 \mathrm{mM}$ $\mathrm{MgCl}_{2}, 20 \mathrm{mM} \mathrm{KCl}, 10 \mathrm{mM} \mathrm{Na} 2 \mathrm{HPO}_{4}-\mathrm{NaH}_{2} \mathrm{PO}_{4}$ at $\mathrm{pH}$ 8.0) containing $1 \mathrm{mg}$ of yeast tRNA (Invitrogen Japan). The mixtures were gently shaken for $10 \mathrm{~min}$ at $37^{\circ} \mathrm{C}$. Streptavidin magnetic beads were collected by magnet, and $10 \mu \mathrm{L}$ of supernatant was used as unbound fraction (UB). Streptavidin magnetic beads were washed with $100 \mu \mathrm{L}$ of wash buffer $(20 \mathrm{mM}$ Tris- $\mathrm{HCl}$ at $\mathrm{pH} 8.0,0.2 \mathrm{M} \mathrm{KCl})$. Ten microliters of $\mathrm{H}_{2} \mathrm{O}$ was added to streptavidin magnetic beads, and the suspension was used as bound fraction (B). The UB and B samples were mixed with SDS-PAGE loading buffer. The sample was heated for $5 \mathrm{~min}$ at $100^{\circ} \mathrm{C}$ and subjected to a $15 \%$ SDS gel electrophoresis. Hfq-His 6 was visualized by SilverQuest silver staining kit (Life Technologies).

\section{ACKNOWLEDGMENTS}

We thank Susan Gottesman and Donald Court for critical reading of the manuscript and helpful comments. This work was supported by Grants-in-Aid from the Ministry of Education, Culture, Sports, Science and Technology of Japan (to H.A. and T.M.) and Takeda Science Foundation (T.M.). 
Received March 18, 2015; accepted May 31, 2015.

\section{REFERENCES}

Abe H, Abo T, Aiba H. 1999. Regulation of intrinsic terminator by translation in Escherichia coli: transcription termination at a distance downstream. Genes Cells 4: 87-97.

Aiba H, Adhya S, de Crombrugghe B. 1981. Evidence for two functional gal promoters in intact Escherichia coli cells. J Biol Chem 256: 11905-11910.

Aiba H, Fujimoto S, Ozaki N. 1982. Molecular cloning and nucleotide sequencing of the gene for E. coli cAMP receptor protein. Nucleic Acids Res 10: 1345-1361.

Brosius J, Dull TJ, Sleeter DD, Noller HF. 1981. Gene organization and primary structure of a ribosomal RNA operon from Escherichia coli. $J$ Mol Biol 148: 107-127.

Chao Y, Papenfort K, Reinhardt R, Sharma CM, Vogel J. 2012. An atlas of Hfq-bound transcripts reveals $3^{\prime}$ UTRs as a genomic reservoir of regulatory small RNAs. EMBO J 31: 4005-4019.

Datsenko KA, Wanner BL. 2000. One-step inactivation of chromosomal genes in Escherichia coli K-12 using PCR products. Proc Natl Acad Sci 97: 6640-6645.

d'Aubenton Carafa Y, Brody E, Thermes C. 1990. Prediction of rho-independent Escherichia coli transcription terminators. A statistical analysis of their RNA stem-loop structures. J Mol Biol 216: 835-858.

Gottesman S, Storz G. 2010. Bacterial small RNA regulators: versatile roles and rapidly evolving variations. Cold Spring Harb Perspect Biol 1: 1-16.

Guo MS, Updegrove TB, Gogol EB, Shabalina SA, Gross CA, Storz G. 2014. MicL, a new sigmaE-dependent sRNA, combats envelope stress by repressing synthesis of Lpp, the major outer membrane lipoprotein. Genes Dev 28: 1620-1634.

Ishikawa H, Otaka H, Maki K, Morita T, Aiba H. 2012. The functional Hfq-binding module of bacterial sRNAs consists of a double or single hairpin preceded by a U-rich sequence and followed by a $3^{\prime}$ poly (U) tail. RNA 18: 1062-1074.

Kawamoto H, Morita T, Shimizu A, Inada T, Aiba H. 2005. Implication of membrane localization of target mRNA in the action of a small RNA: mechanism of post-transcriptional regulation of glucose transporter in Escherichia coli. Genes Dev 19: 328-338.

Kawamoto H, Koide Y, Morita T, Aiba H. 2006. Base-pairing requirement for RNA silencing by a bacterial small RNA and acceleration of duplex formation by Hfq. Mol Microbiol 61: 1013-1022.

Maki K, Morita T, Otaka H, Aiba H. 2010. A minimal base-pairing region of a bacterial small RNA SgrS required for translational repression of ptsG mRNA. Mol Microbiol 76: 782-792.

Masse E, Gottesman S. 2002. A small RNA regulates the expression of genes involved in iron metabolism in Escherichia coli. Proc Natl Acad Sci 99: 4620-4625.

Masse E, Escorcia FE, Gottesman S. 2003. Coupled degradation of a small regulatory RNA and its mRNA targets in Escherichia coli. Genes Dev 17: 2374-2383.

Morita T, Maki K, Aiba H. 2005. RNase E-based ribonucleoprotein complexes: mechanical basis of mRNA destabilization mediated by bacterial noncoding RNAs. Genes Dev 19: 2176-2186.

Morita T, Mochizuki Y, Aiba H. 2006. Translational repression is sufficient for gene silencing by bacterial small noncoding RNAs in the absence of mRNA destruction. Proc Natl Acad Sci 103: 4858-4863.

Otaka H, Ishikawa H, Morita T, Aiba H. 2011. PolyU tail of rho-independent terminator of bacterial small RNAs is essential for Hfq action. Proc Natl Acad Sci 108: 13059-13064.
Papenfort K, Sun Y, Miyakoshi M, Vanderpool CK, Vogel J. 2013. Small RNA-mediated activation of sugar phosphatase mRNA regulates glucose homeostasis. Cell 153: 426-437.

Platt T. 1986. Transcription termination and the regulation of gene expression. Annu Rev Biochem 55: 339-372.

Post LE, Strycharz GD, Nomura M, Lewis H, Dennis PP. 1979. Nucleotide sequence of the ribosomal protein gene cluster adjacent to the gene for RNA polymerase subunit $\beta$ in Escherichia coli. Proc Natl Acad Sci 76: 1697-1701.

Rabhi M, Espeli O, Schwartz A, Cayrol B, Rahmouni AR, Arluison V, Boudvillain M. 2011. The Sm-like RNA chaperone Hfq mediates transcription antitermination at Rho-dependent terminators. EMBO J 30: 2805-2816.

Reynolds R, Bermudez-Cruz RM, Chamberlin MJ. 1992. Parameters affecting transcription termination by Escherichia coli RNA polymerase. I. Analysis of 13 rho-independent terminators. J Mol Biol 224: 31-51.

Rosenberg M, Court D. 1979. Regulatory sequences involved in the promotion and termination of RNA transcription. Annu Rev Genet 13: 319-353.

Said N, Rieder R, Hurwitz R, Deckert J, Urlaub H, Vogel J. 2009. In vivo expression and purification of aptamer-tagged small RNA regulators. Nucleic Acids Res 37: e133.

Sauer E, Weichenrieder O. 2011. Structural basis for RNA 3'-end recognition by Hfq. Proc Natl Acad Sci 108: 13065-13070.

Sledjeski D, Gottesman S. 1995. A small RNA acts as an antisilencer of the H-NS-silenced rcsA gene of Escherichia coli. Proc Natl Acad Sci 92: 2003-2007.

Storz G, Gottesman S. 2006. Versatile roles of small RNA regulators in bacteria. Cold Spring Harbor Laboratory Press, Cold Spring Harbor, NY.

Sun Y, Vanderpool CK. 2011. Regulation and function of Escherichia coli sugar efflux transporter A (SetA) during glucose-phosphate stress. J Bacteriol 193: 143-153.

Vanderpool CK, Gottesman S. 2004. Involvement of a novel transcriptional activator and small RNA in post-transcriptional regulation of the glucose phosphoenolpyruvate phosphotransferase system. Mol Microbiol 54: 1076-1089.

Vanderpool CK, Gottesman S. 2007. The novel transcription factor SgrR coordinates the response to glucose-phosphate stress. J Bacteriol 189: 2238-2248.

Vassinova N, Kozyrev D. 2000. A method for direct cloning of fur-regulated genes: identification of seven new fur-regulated loci in Escherichia coli. Microbiology 146 Pt 12: 3171-3182.

Vincent HA, Phillips JO, Henderson CA, Roberts AJ, Stone CM, Mardle CE, Butt LE, Gowers DM, Pickford AR, Callaghan AJ. 2013. An improved method for surface immobilisation of RNA: application to small non-coding RNA-mRNA pairing. PLoS One 8: e79142.

Vogel J, Luisi BF. 2011. Hfq and its constellation of RNA. Nat Rev Microbiol 9: 578-589.

Vogel J, Bartels V, Tang TH, Churakov G, Slagter-Jager JG, Huttenhofer A, Wagner EG. 2003. RNomics in Escherichia coli detects new sRNA species and indicates parallel transcriptional output in bacteria. Nucleic Acids Res 31: 6435-6443.

Waters LS, Storz G. 2009. Regulatory RNAs in bacteria. Cell 136: 615-628.

Yager TD, von Hippel PH. 1991. A thermodynamic analysis of RNA transcript elongation and termination in Escherichia coli. Biochemistry 30: 1097-1118.

Zuker M. 2003. Mfold web server for nucleic acid folding and hybridization prediction. Nucleic Acids Res 31: 3406-3415. 

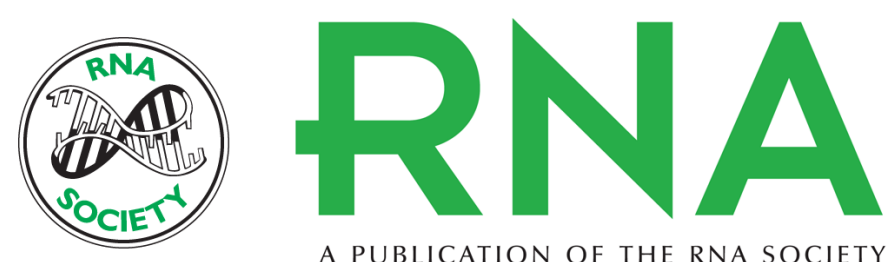

A PUBLICATION OF THE RNA SOCIETY

\section{Insights into transcription termination of $\mathrm{Hfq}$-binding sRNAs of Escherichia coli and characterization of readthrough products}

Teppei Morita, Masaki Ueda, Kento Kubo, et al.

RNA 2015 21: 1490-1501 originally published online June 23, 2015

Access the most recent version at doi:10.1261/rna.051870.115

\begin{aligned} & \hline References $\begin{array}{l}\text { This article cites } 37 \text { articles, } 16 \text { of which can be accessed free at: } \\ \text { http://rnajournal.cshlp.org/content/21/8/1490.full.html\#ref-list-1 }\end{array} \\ &$ Open Access Freely available online through the $R N A$ Open Access option. \\ & $\begin{array}{r}\text { Creative } \\ \text { Commons } \\ \text { License }\end{array} \begin{array}{l}\text { This article, published in } R N A \text {, is available under a Creative Commons License } \\ \text { (Attribution } 4.0 \text { International), as described at } \\ \text { http://creativecommons.org/licenses/by/4.0/. }\end{array} \\ &$ Email Alerting \\ & Service \end{aligned}$\quad \begin{gathered}\text { Receive free email alerts when new articles cite this article - sign up in the box at the } \\ \text { top right corner of the article or click here. }\end{gathered}$

